\title{
Reviewing the distinction awards system in England and Wales, 1978 and 1979
}

\author{
S BOURNE, P BRUGGEN
}

The DHSS has not published a report of the awards for 1979 but some figures are obtainable on request. Since our last comments $^{1}$ figures have been given for 1978 and 1979 and there has been an important statement from Sir Stanley Clayton. ${ }^{2}$ Furthermore, the Central Committee for Hospital Medical Services has set up a working party and regional committees for hospital medical services have been asked for their views before proposals are formulated.

For 1979 there are details of the distribution of awards to some subspecialties of the previous groupings. We have tabulated the results showing, in descending order of success, specialties listed in previous years (table). The fresh details are for subdivisions in general surgery, general medicine, pathology, and psychiatry. Accident and emergency consultants have now been separated from orthopaedic surgery and, thereby, are almost off the bottom of the chart. We have also repeated some figures for 1974 and 1978 and some calculations from our previous papers for comparison; the performance of certain larger groupings may be of more interest and importance than the wide variations between all the smaller ones. ${ }^{3-6}$

\section{Award distribution pattern}

The changes are unimpressive but suggest some levelling up, especially between 1978 and 1979. The score has fallen at the top of the table, particularly in the small groups at the very top; the resultant gains are scattered down the rest of the list. At the bottom, psychiatrists, geriatricians, and venereologists have continued to lose ground while anaesthetists have gained a little. Community physicians have picked up a bit but still do not receive more than a share of the extra awards put in to enlarge the pool when they were included in 1974.

General medicine (1264 consultants) took an unusual fall in 1979 (minus 6.4 awards points per cent*), shifting from seventh to eighth place and changing places with radiotherapy. Otherwise the fall in scores at the top of the table still leaves the order largely unchanged. In previous years we banded the top seven specialties and the bottom seven to show the comparison. To follow the same groups this year we have made the calculation for the first six specialties together with general medicine (now eighth, formerly seventh).

The subdivisions in pathology will be of primary interest to pathologists and we do not see any obvious principles to extrapolate from them.

In "mental health," the classification until 1978, the 1979 subdivisions show that general psychiatrists ("mental illness")

$* A+$ award $=4$ points; $A$ award $=3$ points $B$ award $=2$ points $C$ award $=$ 1 point.

The Tavistock Clinic, London NW3 5BA

$S$ BOURNE, MRCP, FRCPSYCH, consultant psychotherapist

\footnotetext{
Adolescent Unit, Hill End Hospital, St Albans, and The Tavistock Clinic

P BRUGGEN, DCH, FRPSYCH, consultant psychiatrist
}

score much better than the smaller subspecialties and 5.3 points $\%$ higher than the average for psychiatrists taken as a whole. In so far as these awards are an index, child and adolescent psychiatrists share with accident and emergency consultants the distinction of forming the extreme tail of the profession.

No figures are available for the distribution of awards by region and the position of women consultants has not become at all clear from computerised data so we cannot check whether matters have improved. "Hand-produced" figures disclose that in 1978 men scored almost twice as many awards points \% as women. ${ }^{78}$

\section{Advisory committee composition}

The regional advisory committees are selected at the DHSS from award-holding nominees supplied by the regional committee for hospital medical services, and the chairman of the system (at present Sir Stanley Clayton) tries to ensure a fair balance of interests in these committees. Unfortunately, the system seems to make this difficult. For some years we have pointed out an imbalance whereby the groups at the top of the score table are also disproportionately represented on the committees. These top groups, represented on the committees two to three times as strongly, pro rata, as the bottom groups, also get well over twice as many awards points. Some change has occurred; in the past two years the representation of the top seven specialties has fallen from $177 \%$ of the "fair number" in 1977 to $170 \%$ in 1978 and to $157 \%$ in 1979 . Movement is slow and, at the other end, representation of the bottom seven specialties has risen only from $60 \%$ of the "fair rate" in 1977 to $61 \%$ in 1978 and to $62 \%$ in 1979 . As with the awards themselves, the chief recent gain in representation on advisory committees is around the middle of the table.

Women hold only about one in 60 committee seats, though they constitute about one in 10 consultants, and they score badly as a group.

\section{Comments}

The weakness and faults of the system remain unchanged in every important respect.

\section{SECRECY}

Consultants may now examine the local list of awards in the offices of their RHAs, against undertakings of secrecy. Secret information has long been available to over 1000 consultants who take part in all the various advisory committees. The information cannot be studied properly, unlike other confidential material, nor published, like other honours of which our profession is strikingly less coy. This new, restricted, disclosure will have little effect on the adverse results of secrecy and we believe that not many consultants have taken up what may seem like an opportunity to snoop. 


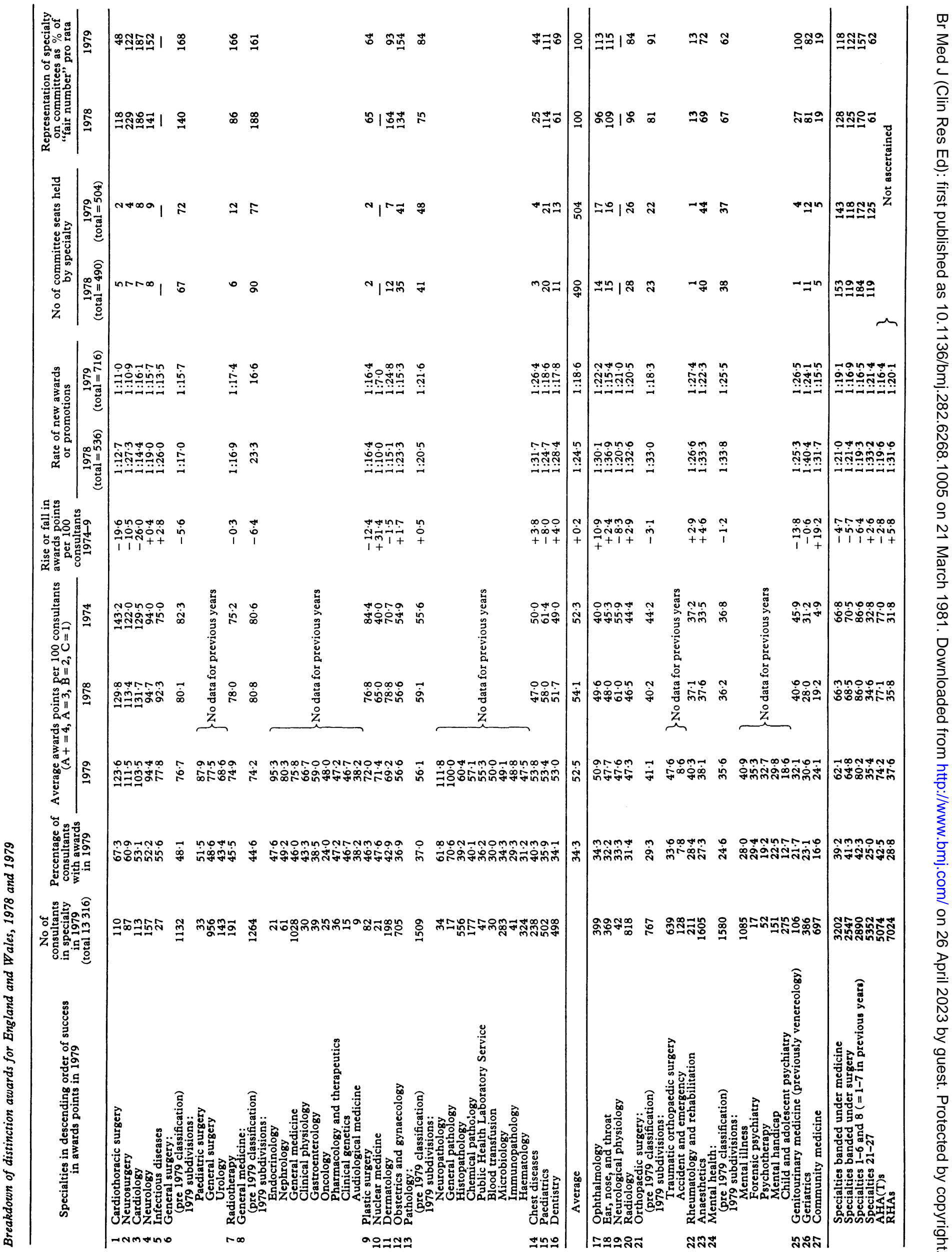


We have readily been given the available statistics in our inquiries over the past few years but again, this year, we have to accept that the data are not yet coming out of the computer. Quite simple facts are still not available. After seven years we have still been unable to verify or refute our calculation that, for example, at least one in three teaching hospital physicians probably has an $\mathrm{A}$ or $\mathrm{A}+$ award at retirement.

\section{QUOTAS AND GUIDELINES}

We believe sincere official reassurances that there are no central quotas for different specialties and that numerical guidelines given to various institutions inviting their nominations are meant to be fairly calculated. Yet we are repeatedly told by advisory committee members that they feel constrained by "the realistic number" of nominations to put forward. Guidelines must influence expectations and the flow of nominations. Guidelines are still issued to the regional advisory committees, to the royal colleges, and to the special committee convened to ensure that the postgraduate teaching hospitals do not suffer neglect. When we last obtained figures (before 1974) there was a disparity of between three and four to one in the nomination rate invited from London teaching hospitals and from the other metropolitan hospitals. We have asked for details of the numerical guidelines for the last year or two to see how they compare; but, regrettably, they are no longer disclosed. If guidelines there must be it might be helpful simply to remind advisory committees of the current award rate for each age group. This could correct prevalent misconceptions about the rarity of higher awards, which are really fairly common over age 55.

\section{BIAS IN THE ADVISORY COMMITTEES}

The regional advisory committees form the principal gateway for success in the system, and the heavy bias in their composition must prejudice the results in favour of continuing the past pattern despite individual efforts to behave fairly. The possibility that bias in composition of committees contributes to bias in the nominations is being studied officially, and there has been a limited redistribution of advisory committee seats in the past two years.

We reiterate our impression of care and integrity in those committee members we know and in what they tell us of everyone else. Any middle-aged consultant scanning the list of committee members will recognise the occasional friend and many acquaintances; he will even recognise a sprinkling of unusual or dissident personalities. But we reiterate our certainty that the system corrupts integrity and that the personal qualities in chairmen and committees are submerged by errors built into the system.

\section{NOMINATION PROCESS}

The secrecy inhibits communication and information in a system already haphazard and unreliable. In each local advisory committee a group of about 15 to 20 people may meet for one day twice a year to set about 1000 colleagues in order of rank. For this nearly impossible task they are rarely equipped with more than whispers and their prejudices, plus a list of eligible names. We have urged a more serious approach to the collection and collation of data but still most committee members often have no idea at all about many of the eligible people. Most members to whom we have spoken still find it baffling to have to make recommendations about totally unknown colleagues. Committees large enough to be "fair" and incorporating an adequate spread of knowledge would also be too large to function properly.

The nominations will often depend on mere impressions formed by one or two people and then on their persuasiveness in committees, given that each person there will have other cases to advocate. Inevitably, the results tend fairly simply to reflect the balance of power and numbers among the existing award holders who form the committees-however hard they may try to be just. It is not surprising that gross mistakes occur constantly; we know nobody who has seen lists of award holders and not been astounded.

Each unsuccessful group of consultants generates its own emotion. Perhaps what is most interesting is the gulf between the good will, honour, and optimism poured into the system, and the impressive unfairness actually operating.

\section{References}

${ }^{1}$ Bourne S, Bruggen P. Distinction awards for England and Wales 1977: observations and a look ahead. Br Med f 1979; i:638-9.

${ }^{2}$ Clayton S. Procedures and criteria for selection of distinction and meritorious service awards. Health Trends 1979;11:73-6.

${ }^{3}$ Bourne S, Bruggen P. Examination of the distinction awards system. $\mathrm{Br}$ Med $\mathcal{F} 1975 ;$ i:162-5

${ }^{4}$ Bruggen P, Bourne S. Further examination of the distinction awards system in England and Wales. Br Med F 1976;i:536-7.

${ }^{5}$ Bruggen $P$, Bourne $S$. Third examination of the distinction awards system in England and Wales. $\mathrm{Br} \mathrm{Med} \mathcal{F} 1977 ; \mathrm{i}: 462-4$.

${ }^{6}$ Bourne S, Bruggen P. Re-examination of the distinction awards system in England and Wales, 1976: the new advisory committees. $\mathrm{Br} \mathrm{Med} \mathcal{F}$ 1978;i :456-7.

${ }^{7}$ Lester E. Sex distribution of distinction awards. Br Med f 1980;280:198.

${ }^{8}$ Bourne S, Bruggen P. Sex distribution of distinction awards. Br Med $\mathcal{F}$ $1980 ; 280: 407$.

(Accepted 23 Fanuary 1981)

\section{Removal expenses}

\section{Part-time doctors}

The current terms and conditions of service do not allow part-time doctors with domestic commitments to claim removal expenses. The DHSS, however, is prepared to consider sympathetically any individual case brought to its attention by employing authorities. If employing authorities are unwilling to approach the DHSS the doctors concerned should, if BMA members, contact their local BMA regional office, and the staff will pursue the matter on their behalf.

\section{Coming back from abroad}

The DHSS has also agreed to consider individual cases on their merits of reimbursement of removal expenses from the port of entry into the UK for doctors from the UK who have undertaken or completed training abroad. As in the above case any doctors in this position should ask their employing authority to raise the matter with the DHSS.

\section{Oxford AHA(T)}

One of the economies introduced by Oxfordshire AHA(T) that led to the threat of the inclusion of the authority in the $B M$ f's Important $^{\prime}$ Notice (17 January, p 245) was its decision not to reimburse certain removal expenses it considered to be discretionary to officers interviewed on or after 1 June 1980. These expenses were: expenses relating to an abandoned purchase (legal costs, survey fees, etc); interest charges on a bridging loan; allowance during search for accommodation (subsistence allowance, visits home, excess daily travelling expenses); and continuing commitments allowance. After protracted discussions with the DHSS and the BMA the AHA decided in December 1980 to rescind its decision, and it was agreed that officers interviewed after 1 June 1980 should now be eligible for help with the expenses listed above within the limits imposed by the regulations in force. Claims, with all supporting vouchers, should be sent to the authority's finance department. 